\title{
Ciudadanía de las mujeres: una revisión desde la ciencia política ${ }^{1}$
}

\section{Women's citizenship: a review from political science}

Cómo citar este artículo en APA: Ramírez, Y. y Acevedo, J. (2021). Ciudadanía de las mujeres: una revisión desde la ciencia política. Analecta Política, 11(20), 109-132. doi: http://dx.doi. org/10.18566/apolit. v11n20.a06

Fecha de recepción: 18.01.2021 Fecha de aceptación: 24.05.2021

\author{
YULY ANDREA RAMÍREZ OSORIO \\ Magíster en Estudios Políticos \\ Docente adscrita a la Secretaría de Educación de Antioquia \\ Correo electrónico: yulyandro@gmail.com
}

\section{JENNY MARCELA ACEVEDO VALENCIA}

Magíster en Estudios Políticos

Docente e investigadora del grupo Laboratorio Universitario de Estudios Sociales

(LUES)

Universidad Católica Luis Amigó Correo electrónico: jenny.acevedova@amigo.edu.co

1 Este artículo hace parte de los resultados de la tesis: "Aproximación Documental a la Categoría Ciudadanía de las Mujeres, para optar al título de Magíster en Estudios Políticos de la Universidad Pontificia Bolivariana, Medellín, Colombia. Este producto se inscribe en el proyecto de investigación: "Ciudadanías femeninas desde la insurgencia: una mirada desde el enfoque de género"; adscrito al grupo de investigación Laboratorio Universitario de Estudios Sociales (LUES) Facultad de Educación y Humanidades, Universidad Católica Luis Amigó 


\section{Resumen}

La exclusión de las mujeres en el ejercicio de la ciudadanía, lejos de ser accidental, ha sido parte integral de las tradiciones históricas y ha condicionado el modo en que las mujeres se integran en la vida pública. En la Edad Moderna, con la llegada del pensamiento liberal y sus ideas de progreso, libertad e igualdad, las mujeres comenzaron a cuestionar el orden establecido y a organizarse para reclamar sus derechos, así emprendieron un largo camino político que trescientos años después continúa en construcción. Este artículo proviene de una investigación documental cualitativa y presenta un barrido histórico acerca del concepto de ciudadanía desde los aportes de la ciencia política y las perspectivas feministas. En los resultados, se identifica reflexiones frente a la manera tradicional de entender el espacio público-privado, además, aquellos elementos como los discursos, las prácticas y las relaciones sociales que integran esta categoría.

Palabras clave: ciudadanía, ciudadanía de la mujer, feminismo, público-privado, ciencia política.

\section{Abstract}

Far from being an accidental issue, the exclusion of women from the exercise of citizenship has been an integral part of historical traditions. Moreover, it has conditioned the way in which women are integrated into public life. In the Modern Age, with the arrival of liberal thought and its ideas of progress, freedom and equality, women began to question the established order and to stand up for their rights, thus embarking on a long political path that continues to be built three hundred years later. This article results from a qualitative documentary research and presents a historical account of the concept of citizenship from the contributions of political science and feminist perspectives. As part of the results, reflections on the traditional way of understanding the public-private space are evidenced, in addition to elements such as discourses, practices and social relations that make up this category.

Keywords: citizenship, women's citizenship, feminism, public-private, political science. 


\section{Introducción}

Al revisar el papel político de la mujer a lo largo de la historia, se identifica que ha estado relegada a un segundo plano, que ha vivido a la sombra de las decisiones tomadas por los hombres, sometida a la aprobación del otro, en una posición subsidiaria, de ayuda, de cuidado, desprovista de un rol principal, habilitada para hacerse cargo de la vida de los otros, pero ausente a la hora de participar en los asuntos públicos.

Esta situación puede verificarse en el concepto clásico de espacio público y privado en el que se asignan funciones sociales a hombres y mujeres de manera diferenciada, asunto que está asociado, por lo general, a la construcción naturalizada del género. ${ }^{1}$ Así, en el espacio público, entendido como un escenario en el que se despliegan prácticas políticas, se ejerce la ciudadanía, el poder, se evidencian las formas más prestigiadas de sociabilidad y de cultura, que han estado vinculadas a la identidad social masculina, mientras que el espacio privado, entendido como lo doméstico, lo no civilizado ni civil, ha sido asociado con lo femenino (Aguado, 2005; Dietz y Vericat, 1990; Mouffe, 1999). Esta explicación entre lo público y lo privado se sustenta en la conformación de dualismos o pares opuestos propios del surgimiento del pensamiento liberal clásico en el que se estructuran, por ejemplo, binarios como pasivo/activo, racional/irracional, pensamiento/sentimiento, razón/emoción, cultura/naturaleza, objetivo/subjetivo, abstracto/concreto, entre otros, que, según argumenta Olsen (2000), obedecen a construcciones sociales y culturales que ponen en cuestión básicamente dos asuntos: a) que los dualismos denotan una identificación sexual, es decir, que lo masculino se asocia con una cara de la moneda (activo, racional, pensamiento, razón, cultura, objetivo y abstracto), mientras que lo femenino con la otra (pasivo, irracional, sentimiento, emoción, naturaleza, subjetivo y concreto); b) que estos dualismos no solo dividen la sociedad entre dos términos, sino que están situados en un orden jerárquico, el cual se traduce en dominación y definición; en este caso, una dominación y definición referida a lo que se considera como femenino que ocupa y connota algo de menor categoría.

1 Su uso explícito rechaza las explicaciones biológicas, del estilo de las que encuentran un denominador común para diversas formas de subordinación femenina en los hechos de que las mujeres tienen capacidad para parir y que los hombres tienen mayor fuerza muscular. En lugar de ello, el género pasa a ser una forma de denotar las "construcciones culturales", la creación totalmente social de ideas sobre los roles apropiados para mujeres y hombres. Es una forma de referirse a los orígenes exclusivamente sociales de las identidades subjetivas de hombres y mujeres. Género es, según esta definición, una categoría social impuesta sobre un cuerpo sexuado (Scott, 2015, pp. 6-7). 


\section{2 | Yuly Andrea Ramírez Osorio y Jenny Marcela Acevedo Valencia Ciudadanía de las mujeres: una revisión desde la ciencia política}

Esta forma de entendimiento sobre la división entre lo público y lo privado es la visión que prevalecía en la antigua Grecia, donde la mujer no tenía capacidad política y era considerada un ser pasional e irracional. En la Ilustración, cuando surgió el liberalismo con su postulado de libertad e igualdad, algunos de los autores no incluyeron a las mujeres en sus propuestas y caracterizaron la esencia de su existencia por medio de la categorización como especie: las mujeres no eran consideradas individuos con voluntad propia, sino seres de naturaleza irracional. El propio Rousseau afirmaba (1762/1985) que las mujeres, a diferencia de los hombres, no podían controlar sus "deseos ilimitados", ni, en consecuencia, desarrollar la moralidad que requiere la sociedad civil. Esto señala, según autoras como Aguado (2005), un discurso patriarcal que no solo no objeta la desigualdad, sino que quiere preservarla y legitimarla.

Sostiene Aguado (2005) que estas ideas androcéntricas dejaron por mucho tiempo a las mujeres por fuera del plano de la ciudadanía. Justo después de la Revolución francesa, Olympe de Gouges redactó la traducción en clave de las mujeres de la Declaración de los Derechos del Hombre y del Ciudadano de 1789 reclamando la igualdad entre los sexos y recurriendo a la naturaleza como paradigma normativo, como se hace en cada planteamiento ilustrado, ya no para justificar la desigualdad, sino para deslegitimar las jerarquías sociales y culturales. A partir de esta época, se desencadena una serie de acciones que exigen la reivindicación de los derechos que habían sido negados por esta concepción reduccionista.

De esta manera, las teorías feministas se concentran en plantear una crítica al pensamiento liberal por la presunción de universalismo, debido a que este confiere a la esfera privada los asuntos que pueden dividir a las personas, y es justamente en ese ámbito donde se ha destinado el rol principal para la mujer. Además de ser un espacio tradicionalmente subvalorado, esta división ha tenido una doble consecuencia: a) las políticas igualitarias tienen vedada la entrada de la mujer en el mundo de lo público; b) lo público se constituye en un espacio masculino escasamente permeable al género, lo que perjudica especialmente a las mujeres, que siguen engrosando los bajos índices de participación política en la mayoría de los países del mundo (Cano, 2017).

Este panorama es de utilidad para plantear que la categoría ciudadanía de las mujeres ha tomado cada vez más visibilidad y ha sido objeto de interés para la ciencia política, toda vez que en los últimos años se reportan artículos resultados de investigaciones que ponen en el ojo del huracán las desigualdades políticas y la preponderancia de un sistema de exclusión y pobreza que sigue segregando a las mujeres del mundo de la política. En este sentido, Lau y Rodríguez (2017) ana- 
lizan el sufragio de las mujeres en la Constitución mexicana de 1917, y destacan tanto los argumentos en contra como a favor que se plantearon frente al derecho al voto. De esta manera, se reconoce que la construcción de ciudadanía en este caso está asociada con una clase media ilustrada que buscaba abrir canales de participación para mejorar la condición de las mexicanas, privilegiando el acceso al sufragio como una lucha central en sus demandas. En consonancia, Guerra (2019) también analiza la historia del sufragio femenino, pero en países como Perú en las décadas de 1930 a 1950. Para este periodo, el sufragio y el feminismo se entienden como un proceso tardío comparado con el panorama internacional; también se reconoce el ejercicio de ciudadanía desde la lucha por los derechos.

Otro estudio a destacar es el de Manzanera et al. (2015) en el que se analiza el estatuto de ciudadanía de mujeres inmigrantes en España. Se identifica cómo la crisis económica y el rol de inmigrante acentúan las desigualdades de género y ubican a las mujeres ante riesgos y vulnerabilidades. Hay limitaciones a derechos fundamentales como el sufragio, la salud y la protección desde las entidades públicas hacia las mujeres inmigrantes, es decir, se intensifican riesgos a la ciudadanía de las mujeres desde ámbitos estructurales, lo que pone en cuestión la debilidad de esta categoría ante cambios socioeconómicos y políticos.

En esta revisión de antecedentes, también se ubica en Colombia el estudio de Posada y Carmona (2018), quienes mencionan que las mujeres son sometidas a violencia de género en conflictos armados, en que se fortalecen las prácticas patriarcales. Dicha violencia se ejemplifica en la supresión de derechos y limitación del rol de ciudadanas y agentes sociales. Asimismo, Corena y Suárez (2018) muestran que en contextos de conflicto armado las mujeres son victimizadas por su género y se encuentran barreras jurídicas que limitan el ejercicio pleno de la ciudadanía, debido a que los sistemas jurídicos obedecen a patrones sociales relacionados con una cultura predominantemente masculina.

También es relevante revisar dos estudios recientes que incluyen la perspectiva interseccional en el análisis de la configuración de ciudadanía de personas trans. En este caso, Constant (2019) da cuenta de algunas experiencias de mujeres trans respecto del cambio legal de identidad en México y el ejercicio de sus derechos entendidos desde el concepto de ciudadanía, y concluye que existen desafíos desde el punto de vista de una comprensión distinta del género para la consecución de una democracia inclusiva sustantiva, que, además, ponga atención a las características sociales, económicas, étnicas, entre otras, que influyen en la posibilidad de realizar el cambio legal de identidad como parte de la experiencia ciudadana. Y Mestre-Malfran y Oliveira (2020) abordan los usos y efectos de la Resolución 126 


\section{4 | Yuly Andrea Ramírez Osorio y Jenny Marcela Acevedo Valencia Ciudadanía de las mujeres: una revisión desde la ciencia política}

de 2008 del Ministerio de Salud Pública para la atención a transexuales. A partir de estos análisis, los autores concluyen que urge la incorporación en las políticas públicas de una perspectiva interseccional (social y culturalmente construidas) como garantía de una agenda inclusiva y transformadora de las vulnerabilidades que limitan las vidas y los derechos de esta población.

Se entiende que los análisis actuales sobre ciudadanía desde perspectivas de género e interseccional permiten ubicar en contextos situados y específicos los obstáculos que deben enfrentar las mujeres para garantizar sus derechos, asunto que contribuye a problematizar esta categoría y a entender que la experiencia de la ciudadanía pasa por el reconocimiento de una democracia inclusiva que modifique la comprensión acerca del género.

Estos hechos se constituyen en argumento de peso que permiten plantear que el objetivo de este artículo está orientado a realizar una aproximación documental al concepto de ciudadanía de las mujeres, a partir de los significados que esta categoría ha adquirido en la historia gracias a las diferentes escuelas de pensamiento y autores representativos en la ciencia política, hasta llegar a las interpretaciones y apropiaciones realizadas por algunas corrientes feministas. Una perspectiva de género que contribuye a revisar las connotaciones históricas, sociales y culturales de la categoría ciudadanía de las mujeres, que en todo caso aporta a las reflexiones sobre el poder y las desigualdades y los intereses que se han constituido en los análisis de la ciencia política.

\section{Metodología}

A partir de lo expuesto, este artículo se apoya metodológicamente en una investigación de corte cualitativo en modalidad documental, sustentada en un paradigma interpretativo que permite hacer aproximaciones a una situación social determinada para explorarla, describirla y comprenderla de manera inductiva; en este caso, el estudio se apoyó en la lectura de fuentes secundarias para reconocer los aportes que diferentes autores han realizado a la categoría ciudadanía de las mujeres.

Para ello, se rastreó la información en bases de datos académicas como Scielo, EBSCO, Google Académico y Redalyc. Se usaron términos de búsqueda como "participación política", "mujeres", "ciudadanía" y "feminismos", y se limitaron temporalmente los resultados a aquellos artículos publicados en español entre 
$2000^{2}$ y 2020. El resultado fue el análisis de 51 textos, en los que se identificaron 113 palabras clave, de las cuales las más utilizadas son las siguientes: "género" (14), "participación política" (8), "ciudadanía" y "ley de cuotas" (6) y "mujeres" (5); el resto lo ocupan otras palabras clave que no tienen mayor representatividad para el estudio.

También se encontró que el número de publicaciones ha ido aumentando a lo largo del tiempo, así: entre 2000 y 2005: 6; entre 2006 y 2010: 7; entre 2011 y 2015: 9; entre 2016 y 2020: $14^{3}$ (figura 1). De esta manera, en los países del continente suramericano que más publicaciones se encontró fue Argentina, con 12, seguido de Colombia con 10; también se encontraron publicaciones en Europa, Centroamérica y Norteamérica (figura 2).

Figura 1. Año de publicación.

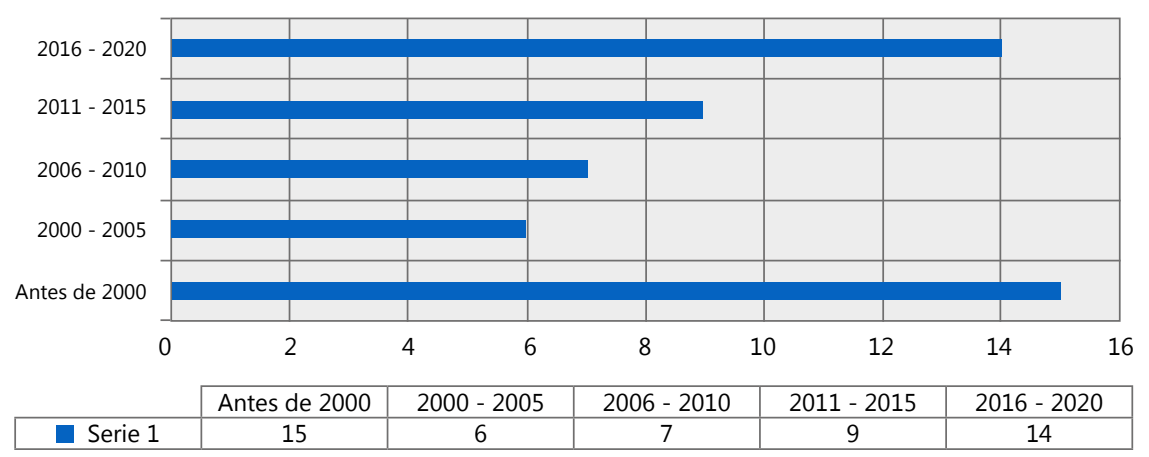

2 Si bien se delimitó la pesquisa bibliográfica entre 2000 y 2020, se consideró bibliografía de autores representativos de la ciencia política antes de esa fecha de suma importancia en el recorrido histórico de la categoría ciudadanía y por ello se integran en el artículo.

3 El artículo de revisión se concentró en organizar, revisar y analizar 51 documentos (entre libros, artículos resultados de investigación, ponencias y videos), sin embargo, no significa que no exista más producción académica relacionada con el tema en estudio. 


\section{6 | Yuly Andrea Ramírez Osorio y Jenny Marcela Acevedo Valencia}

Ciudadanía de las mujeres: una revisión desde la ciencia política

Figura 2. País de publicación.

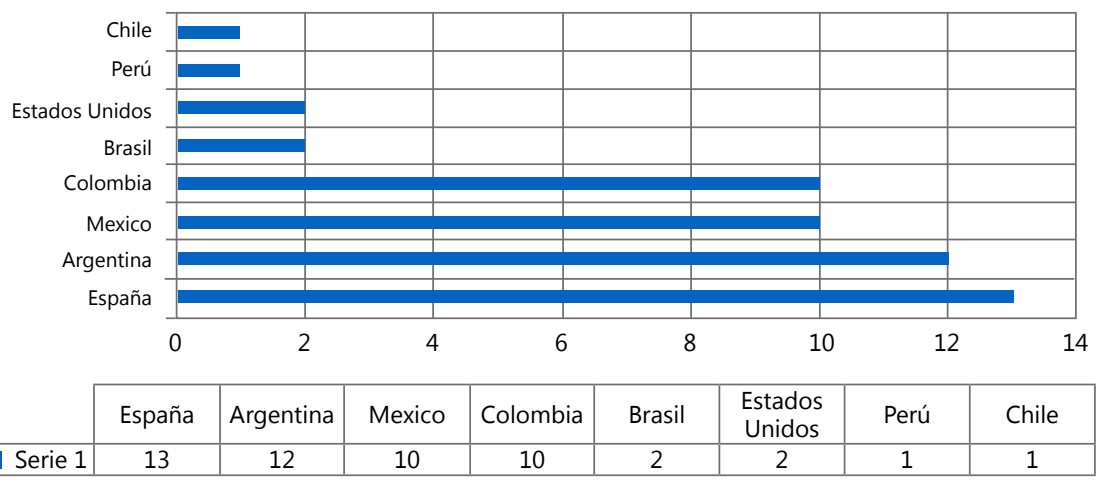

Posteriormente, se utilizó una matriz categorial para la clasificación y el análisis de las fuentes documentales, en la cual se establecieron categorías, códigos y subcódigos de análisis, para facilitar la interpretación, el reconocimiento de relaciones intertextuales y las comparaciones de las diferentes posturas frente al concepto de ciudadanía.

La información se dividió en tres categorías: ciudadanía, ciudadanía de las mujeres y mujer. A su vez, cada categoría se subdividió en dos niveles: códigos y subcódigos, lo que facilitó la interpretación e interconexión de los documentos, como se evidencia en la figura 3.

Lo anterior posibilitó la elaboración de los capítulos de resultados que se dividen de la siguiente manera. Ciudadanía: una mirada histórica desde la ciencia política en que se aborda desde la democracia ateniense hasta la Edad Moderna con el advenimiento de la teoría liberal. Y Ciudadanía de las mujeres desde perspectivas feministas en que se presenta un conjunto de críticas realizadas a la teoría liberal, entre ellos debates como el universalismo del sujeto ciudadano, la dicotomía entre espacio público y privado, además de plantear las demandas actuales de los movimientos feministas y el papel de las redes sociales en la visibilización pública de las reivindicaciones sociales. Finalmente, se presenta un apartado con las conclusiones. 
Figura 3. Categorías y subcategorías.

MATRIZ CATEGORIAL

\begin{tabular}{|c|c|c|}
\hline \multicolumn{3}{|c|}{ MATRIZ CATEGORIAL } \\
\hline CATEGORÍA & CóDIGO & SUBCóDIGO \\
\hline \multirow[t]{2}{*}{ A. CIUDADANía } & A.a. Definición & $\begin{array}{l}\text { A.a.a. Tradición formal-institucional } \\
\text { A.a.b. Democrática } \\
\text { A.a.c. Intercultural } \\
\text { A.a.d. Multicultural } \\
\text { A.a.e. Diferenciada }\end{array}$ \\
\hline & $\begin{array}{l}\text { A.b. Contexto político e } \\
\text { ideológico }\end{array}$ & $\begin{array}{l}\text { A.b.a. Liberalismo } \\
\text { A.b.b. Feminismo }\end{array}$ \\
\hline \multirow[t]{3}{*}{$\begin{array}{l}\text { B. CIUDADANÍA DE LAS } \\
\text { MUJERES }\end{array}$} & B.a. Prácticas & B.a.a. Público-privado \\
\hline & B.b. Dificultades & $\begin{array}{l}\text { B.b.a. Desigualdad } \\
\text { B.b.b. Universalidad } \\
\text { B.b.c. Cargos públicos } \\
\text { B.b.d. Patriarcado }\end{array}$ \\
\hline & B.c. Valores & $\begin{array}{l}\text { B.c.a. Identidad } \\
\text { B.c.b. Heterogeneidad } \\
\text { B.c.c. Organización }\end{array}$ \\
\hline C. MUJER & C.a. Papel en la Historia & $\begin{array}{l}\text { C.a.a. Edad Antigua } \\
\text { C.a.b. Edad Media } \\
\text { C.a.c. Revolución Francesa } \\
\text { C.a.d. Modernidad }\end{array}$ \\
\hline
\end{tabular}

\section{Ciudadanía: una mirada histórica desde la ciencia política}

La ciudadanía es un concepto polisémico que ha recibido diferentes interpretaciones a lo largo de la historia, por ejemplo, autores como Bárcena (1997) señalan al respecto que es un concepto "múltiple, dinámico, intersubjetivo y socio históricamente contextualizado, lo cual le permite ser interpretado y asumido de diferentes formas" (p. 76).

Los primeros en recibir el calificativo de ciudadanos fueron los habitantes de Atenas, en la antigua Grecia, lugar donde surgió la democracia en el siglo $\mathrm{V}$ a. C. Las decisiones sobre el curso de la ciudad (polis) se tomaban por medio de la participación directa de los ciudadanos, pero solo formaban parte de esta colectividad política los varones libres, mayores de edad, propietarios de trabajo ajeno (esclavos) e hijos de padre y madre ateniense (un porcentaje reducido de la población), así que quedaban excluidas las mujeres, los extranjeros y los esclavos. 


\section{8 | Yuly Andrea Ramírez Osorio y Jenny Marcela Acevedo Valencia Ciudadanía de las mujeres: una revisión desde la ciencia política}

En palabras de Suárez (2004), "debemos decir que tal tipo de democracia era una forma de gobierno limitada y excluyente" (p. 130).

Posteriormente, con la expansión del Imperio romano, comenzó a entenderse la ciudadanía en un contexto de democracia representativa: ${ }^{4}$ eran ciudadanos los habitantes de Roma y del territorio del Imperio. En este contexto, el ciudadano no sería solo aquel que participaba (ciudadano-gobernante), sino aquel que pasó a ser sujeto de derechos (ciudadano-súbdito), al que se le reconoció el derecho al voto, a llevar a cabo contratos legales, a adquirir propiedades y a no ser torturado o azotado, entre otros. Hubo una transición de la polis griega a la civis romana. En cuestión de reconocimiento de derechos, las mujeres, los nativos y los esclavos continuaron perteneciendo a un grupo diferenciado de los llamados hombres libres: para estos tres grupos, la ciudadanía fue ejercida de manera limitada.

Más adelante, la Baja Edad Media (siglos XI-XV) llegó con el desarrollo urbano, el nacimiento de la burguesía y la constitución de las ciudades Estado en Italia, época en la que se fue recuperando la figura de ciudadano que había sido abolida en la Edad Media. Solo los maestros de los gremios profesionales que tenían la capacidad económica suficiente para realizar el pago de los impuestos podían participar en los asuntos públicos. Los ciudadanos de estas ciudades nación renacentistas eran una clase alta y minoritaria, en tanto que los obreros, los campesinos, los artesanos, los pequeños comerciantes y las mujeres en general continuaban relegados desde el punto de vista de los derechos ciudadanos. Estas últimas debían estar bajo el cuidado de esposos y familiares por ser consideradas inferiores por naturaleza a los hombres: su papel se reducía a la reproducción y la crianza de los hijos (Parrado e Isidro, 2014).

Por su parte, la Edad Moderna es un momento álgido para la historia por los cambios y las invenciones que se dieron en los planos social, religioso, intelectual, científico y político. Surgió el pensamiento liberal en defensa de los derechos y de las libertades individuales, en el que destacan algunos pensadores de la filosofía política como John Locke, llamado padre del liberalismo clásico. Locke contribuyó a justificar las revoluciones burguesas aduciendo que el poder del Estado no era absoluto, sino que debía estar constituido por un rey y un parlamento, y respetar los derechos naturales del hombre a la vida, la propiedad y la libertad. Los hom-

4 Entiéndase por democracia representativa aquella forma de gobierno que presupone la igualdad ante la ley y la ciudadanía extendida a todos los nacionales, sin exclusiones posibles, en la que se valora el procedimiento de las elecciones universales, públicas y periódicas (Suárez, 2004). 
bres necesitan pactar un acuerdo entre ellos y, posteriormente, con el gobernante para garantizar el disfrute de las libertades y, en especial, de la propiedad privada. Al mencionar la libertad y al "hombre" contractuante, Locke (2006) se refiere al varón y deja por fuera a la mujer. Afirma que la mujer es un ser con capacidades mentales y físicas menores que el hombre (p. 82) y que está al servicio de la familia (pp. 78-79).

Otro filósofo que aportó a la teoría política fue Thomas Hobbes. Definió Hobbes (1980) al Estado como el garante de todos los derechos y sostuvo que el poder absoluto lo tiene el monarca y que los súbditos deben obedecer porque en su estado de naturaleza el hombre es un ser egoísta que solo desea satisfacer sus deseos para alcanzar más poder. Su postura respecto del papel de la mujer es contraria a Locke, lo cual se manifiesta cuando, al referirse a quién tiene dominio sobre el hijo (si el padre o la madre), expresa lo siguiente:

Y aunque algunos han atribuido el dominio al varón solamente, por ser del sexo más excelente, se han equivocado en esto. Pues no siempre existe una diferencia de fuerza y prudencia entre el hombre y la mujer, que sea tan clara como para que pueda determinarse sin discusión quién tiene derecho al dominio. (p. 225)

Estas ideas liberales impulsaron las grandes revoluciones del siglo XVIII (la norteamericana y la francesa) y dieron como resultado la independencia de los Estados Unidos en 1776; posteriormente, la finalización de la monarquía francesa y la Declaración de los Derechos del Hombre y del Ciudadano de 1789, en la que se establece que son derechos naturales de todos los hombres la libertad, la propiedad, la seguridad y la resistencia a la opresión.

Este escenario dio paso al nuevo concepto de ciudadanía, pero una vez más la historia designaría para gozar plenamente de tales derechos a los varones adultos y libres con una cierta independencia económica. Después de veinte siglos, las mujeres, los esclavos y los niños continuarían relegados de las decisiones políticas y son forzados a unirse como minorías poblacionales para reclamar el reconocimiento de sus derechos.

En el siglo XXI, perviven las diferentes connotaciones del concepto de ciudadanía. Los precursores clásicos de la concepción tradicional durante el siglo XX la definen así: "La ciudadanía es una condición otorgada a aquellos que son miembros plenos de una comunidad. Todos los que poseen la condición son iguales con respecto a los derechos y deberes de que está dotada esa condición" (Marshall y Bottomore, 1998, p. 37). El concepto está compuesto, entonces, 
por tres dimensiones: la civil, la política y la social, consistentes en los derechos relacionados con las libertades de las personas, la participación en el ejercicio político y el bienestar económico y la seguridad social. Por otra parte, la ciudadanía democrática se entiende como

el resultado de una construcción progresiva a partir del reconocimiento de la historia y la cultura de cada nación y la identificación de unos valores universales que deben ser legitimados en las grandes orientaciones culturales de los países. Esos valores universales en los que se cimienta la consolidación de una democracia participativa giran en torno a tres grandes ejes: los valores relativos a la tolerancia, la autonomía y los derechos humanos; los relacionados con la práctica de la deliberación conjunta, la solución pacíica de los conflictos y la responsabilidad por las decisiones; y los relacionados con la solidaridad. (De Puelles y Urzúa, 1996, p. 10-11)

En esta línea de pensamiento, Mayor (2003) expone el concepto de ciudadanía democrática como una actividad en la que el escenario principal es la vida y los grupos humanos, como la familia, la escuela, el Estado, las organizaciones, los vecinos y las asociaciones, que deben participar en las decisiones para mantener las condiciones democráticas. Sin embargo, la perspectiva democrática integra a todos los subgrupos sociales bajo la pretensión de compartir una igualdad natural y una condición humana común, y así dotar a los individuos de atributos universales relacionados con la teórica igualdad de todos los ciudadanos. En palabras de Aguado (2005):

La teoría liberal concebía al "yo", sujeto de los nuevos derechos políticos, esencialmente neutro en cuanto al sexo, y no sometido por la naturaleza a ninguna autoridad. Pero el liberalismo, preso en sus propias paradojas, por un lado marginaba de la vida política efectiva a amplios sectores de la población; y por otro lado, liberaba a los individuos de los vínculos y dependencias, permitiéndoles conquistar en el ámbito de la privacidad el derecho a tener una vida personal autónoma. (p. 22)

Por su parte, Bobbio (1989) apoya este postulado afirmando que "libertad e igualdad son valores antitéticos en cuanto no se puede realizar con plenitud uno sin limitar fuertemente el otro" (p. 41). En desacuerdo con la visión universalista de los individuos propuesta por el pensamiento liberal, nacen posturas que reclaman un tipo de ciudadanía más específica. Según autores como Sánchez (2006), la ciudadanía intercultural, apoyada en la teoría de la acción comunicativa de 
Habermas, ${ }^{5}$ busca favorecer el diálogo entre diferentes culturas y le apuesta a la construcción de proyectos políticos con posiciones críticas respecto de los fenómenos de exclusión e injusticia social que afectan tanto a los grupos étnicos y culturales distintos como a la población en situación de vulnerabilidad socioeconómica, exclusión e invisibilización política y cultural.

Otra propuesta de ciudadanía es la multicultural, entendida por Kymlicka (1996) como el reconocimiento y apoyo de los Estados multinacionales, multiculturales y poliétnicos a la identidad de los grupos étnicos y minorías nacionales, por medio de la atención diferenciada de los sujetos, para permitirles a los colectivos expresiones de pluralidad y reconocer la diversidad cultural y legitimidad de sus sentidos, prácticas y discursos, necesidades, intereses y aspiraciones. Por su parte, Solé et al. (2013) proponen una ciudadanía diferenciada como el escenario para reivindicar diversos espacios de participación "donde las personas, con sus diferencias culturales, étnicas, de género, de ocupación, etcétera, afirmen sus perspectivas sobre asuntos sociales dentro de instituciones que estimulen la representación de sus distintas voces" (p. 57).

Otros autores que se acercan al concepto son Berger y Luckmann (1983), quienes presentan la condición de ciudadano como una construcción social que se da a través de la apropiación e interiorización de normas, costumbres, discursos, significados, miedos, entre otros, que se viven en la cotidianidad. Por esta razón, el concepto de ciudadanía no puede ser entendido como una condición natural ni universal: "Un ciudadano no es solo lo que las normas le permiten ser, es lo que crea en la relación conflictiva con su mismidad, la alteridad y la otredad" (Mieles y Alvarado, 2011, p. 63).

Este acercamiento a la categoría de ciudadanía desde la ciencia política permite entender y ubicar la discusión en términos históricos y dar hitos importantes que evidencian las desigualdades entre hombres y mujeres, pero al mismo tiempo las posturas académicas que edifican otras nociones frente a la ciudadanía en que intervienen aspectos como lo sociocultural y lo económico. A continuación, se presentan algunos aportes que ha realizado el feminismo a este concepto, visibi-

5 La teoría de la acción comunicativa plantea que, para que la política y la ciudadanía sean efectivas, debe garantizarse a todos los ciudadanos la legitimación de sus derechos sociales, políticos y civiles a partir de la libertad de acción, la libre asociación, la oportunidad de participar en los procesos de formación de opiniones y voluntades, la protección de los derechos individuales y la garantía de las condiciones de vida materiales para el ejercicio de los derechos señalados (Habermas, 1987). 
lizan su estrechez e identifican posturas más coherentes con las realidades y los contextos actuales.

\section{Ciudadanía de las mujeres desde perspectivas feministas}

La exclusión de las mujeres en el ejercicio de la ciudadanía, lejos de ser accidental, ha sido parte integral de las tradiciones históricas y ha condicionado el modo en que las mujeres se integran en ella (Lister, 2004). Por ello, se presentará una lectura feminista sobre los aportes teóricos de distintas autoras que han puesto la atención en la noción de una ciudadanía abstracta y universal propias del pensamiento liberal, que no corresponde con las reivindicaciones sociales, culturales y políticas de los movimientos sociales que, en la conquista de lo público, han edificado una serie de demandas por el reconocimiento de sus derechos desde sus múltiples identidades y apelado a estrategias masivas como las redes sociales.

De esta manera, es importante empezar con los argumentos de autoras como Jiménez (2004), puesto que deja por sentado el papel de las mujeres visto desde una mirada masculina y patriarcal: "Se devela cómo algunos de los pensadores fundantes de la modernidad (Rousseau, Kant, Freud) estaban presos de su ideología patriarcal y consideraron a las mujeres presujetos incapaces de acceder a la racionalidad o a la autonomía moral debido a sus ataduras irreductibles al estado de naturaleza" (p. 51).

En contraposición a este argumento, es relevante traer a colación la traducción que hace Olympe de Gouges a la Declaración de los Derechos del Hombre y del Ciudadano de 1789. En los 17 artículos, cuestiona la neutralidad que se asigna a la palabra "hombre" y propone una nueva actualización en la que se considere a las mujeres como parte del cuerpo social. Así, por ejemplo, dirá en los dos primeros artículos:

\section{Artículo I}

La mujer nace libre y permanece igual al hombre en derechos.

Artículo II

El objetivo de toda asociación política es la conservación de los derechos naturales e imprescriptibles de la Mujer y el Hombre; estos derechos son la libertad, la propiedad, la seguridad y, sobre todo, la resistencia a la opresión. (Aguado, 2005, p. 18) 
No obstante, los posteriores desarrollos de las democracias siguieron mostrando la falta de inclusión de las mujeres en una ciudadanía plena. Así, lo plantea Sánchez (2019):

Cuando las sufragistas exigían el derecho al voto, o más adelante, las feministas de los años setenta demandaban los derechos sociales, no estaban reclamando simplemente ser admitidas en un estatus preexistente, sino que, en realidad, desafiaban todo el orden político, social y jurídico, señalando la necesidad de reformular nuestra gramática política y jurídica. (p. 378)

De este modo, las teorías feministas han puesto el ojo del huracán en los presupuestos y desarrollos del liberalismo y señalan como inviable la noción del sujeto independiente y abstracto como modelo del ciudadano universal, lo cual significa que el paradigma de sujeto en el liberalismo se sustenta, según explica Benhabib (1992), en la experiencia de un grupo específico representado por varones y desde esta noción se ha difundido ficticiamente un consenso social y político hacia el resto de la población. Esta pretensión universalista que engloba el concepto de ciudadanía, además, se caracteriza por ser sustitucionalista y excluyente respecto de otros grupos poblacionales, que, como las mujeres, no comparten las características necesarias para su inclusión en la esfera de lo público.

Por ello, no es novedad señalar que las demandas que hace el feminismo a las democracias contemporáneas se traduzcan, según Sánchez (2019), en la inclusión de un nuevo contrato social constitucional y en que se evidencien asuntos como la distinción entre el trabajo productivo o reproductivo, o el papel de la familia y la economía del cuidado, entre otros asuntos relevantes a la hora de repensar la democracia, lo político y la ciudadanía.

En este contexto, algunas autoras feministas han centrado el debate en la noción de ciudadanía y han planteado elementos problematizadores a las vertientes tradicionales. Así, por ejemplo, Phillips (1996) observa con preocupación la falta de presencia de las mujeres en la toma de decisiones políticas, pues "ningún régimen político o sociedad puede llamarse a sí mismo democrático si sus ciudadanas (por lo general la mitad de la población) no están incluidas en la comunidad política como participantes de pleno derecho" (p. 17). En este sentido, Dietz y Vericat (1990) sostienen la importancia de abrir los márgenes de la ciudadanía liberal hacia el tránsito de una ciudadanía que se construya desde las realidades políticas y sociales, desde los valores y las ideologías que edifican las mujeres, puesto que, al reconocer los contextos en los cuales se configura la ciudadanía, se pueden revisar 


\section{4 | Yuly Andrea Ramírez Osorio y Jenny Marcela Acevedo Valencia Ciudadanía de las mujeres: una revisión desde la ciencia política}

relaciones de poder, transformar miradas estereotipadas de género y reafirmar la consigna "lo personal es político" como una práctica con sentido crítico.

Entretanto, Mouffe (1999) también reflexiona sobre esta categoría y la enmarca desde una perspectiva de la democrática radical, en contraposición con la concepción liberal y del republicanismo cívico, pues, en todo caso, el escenario de una democrática radical presenta el surgimiento de una nueva ciudadanía que contribuye a la extensión de los principios de libertad e igualdad, en que se deben entretejer el ideal del pluralismo y las virtudes cívicas ético-políticas que conlleven la construcción de una hegemonía democrática radical (Acevedo y Castaño, 2020).

En este sentido, Mouffe (1999) argumenta que para este caso la identificación ya no es simplemente bajo el principio del liberalismo que promueve el estatus legal y la posición pasiva de un individuo receptor de derechos, sino bajo una identidad política común de personas que podrían comprometerse de múltiples maneras y con distintas finalidades, en este sentido, la identificación con la república no niega otros procesos de identificación de las mujeres (Acevedo y Castaño, 2020). La ciudadanía radical, por tanto, está relacionada con valores éticos y políticos, que permiten configurar aquellas subjetividades que reconocen una pluralidad de lealtades específicas, puesto que reconoce que el sujeto es construido a través de "diferentes discursos y posiciones, ampliando la interpretación, para que no se reduzca a una identidad o posición singular, es decir, a la clase, la raza o el género" (Mouffe, 1993, p. 11).

Así, estos planteamientos han encontrado un nicho académico para debatir y construir referentes que permitan leer lo que acontece en las prácticas políticas y en los discursos de las mujeres en su cotidianidad, y han abierto un camino frente a la resignificación de lo político desde una perspectiva de género, más allá de un modelo de ciudadanía formal e institucional propio del liberalismo que refuerza los principios de libertad, igualdad y universalidad en que las diferencias identitarias no son incorporadas.

De esta manera, la teoría política feminista se ha nutrido conceptualmente y ha establecido las bases para que las demandas sociales, económicas, culturales y políticas logren impactar la esfera pública y alcanzar el reconocimiento institucional. Al respecto, autoras como Lister (2004) plantean tres modelos de ciudadanía que han estado en el centro de las reivindicaciones, principalmente, de las tres olas del feminismo: 
- Ciudadanía de neutralidad de género, propuesta por el feminismo de la primera ola (forjado en la Ilustración). Surgió a mediados del siglo XVIII en torno a la polémica sobre la naturaleza de la mujer y la jerarquía de los sexos. En este modelo, se considera a las mujeres iguales a los hombres y se cuestionan los privilegios masculinos, por cuanto no se basan en una cuestión biológica o natural.

- Ciudadanía con diferenciación de género, propuesta por el feminismo de la segunda ola (dado desde mediados del siglo XIX hasta la década de 1950). Aborda, entre sus puntos principales, el derecho al voto femenino, reclama el acceso a la educación superior y critica la obligatoriedad del matrimonio.

- Ciudadanía con pluralidad de género, propuesta por el feminismo de la tercera ola (propio de la segunda mitad del siglo XX). Afirma que hombres y mujeres pertenecen a múltiples grupos y poseen múltiples identidades; defiende el derecho al divorcio y al aborto. Sus postulados van desde las políticas públicas que reivindican a la mujer hasta el fin del patriarcado. En este movimiento, fue fundamental la difusión del uso de anticonceptivos, que otorgó a la mujer el control de la natalidad (y la liberación del goce sexual, ya no atado a la reproducción); el divorcio se hizo ley en muchos países; las mujeres empezaron a ser candidatas reales en el mundo político, aunque su porcentaje aún hoy es inferior al de los hombres.

Estos aportes académicos van en consonancia con las proclamas de los movimientos feministas que en la actualidad se enmarcan en la denominada cuarta ola y con ella el "trabajo vivo" (Gil, 2012) o la denuncia constante por parte de las mujeres en las redes sociales. Gil se refiere al trabajo realizado en estas, el cual ha estado orientado a destacar los privilegios de género establecidos históricamente a favor del hombre y rechazar la violencia de género en todos los ámbitos de la vida.

Esta nueva etapa del feminismo tiene como uno de sus elementos principales la vindicación, también activa, de la paridad real, sobre todo, en el ámbito económico y salarial (Sen, 2018). Para que esta paridad se dé más allá de lo cuantitativo, se necesita una educación en la igualdad de oportunidades y con el objetivo de generar conciencia acerca de la corresponsabilidad del trabajo doméstico y de la importancia de la labor política (Scoot, 2015). Además, el feminismo actual tiene una mayor unión con el movimiento LGBTTTI, ${ }^{6}$ queer $^{7}$ y de liberación sexual.

6 Personas lesbianas, gais, bisexuales, travestis, transgénero, transexuales e intersexuales.

7 La teoría queer es la elaboración teórica de la disidencia sexual y la deconstrucción de las identidades estigmatizadas, que a través de la resignificación del insulto consigue reafirmar que la opción sexual distinta es un derecho humano. Las sexualidades periféricas son todas 
Estas demandas en distintos ámbitos de la vida de las mujeres Fraser (2015) las traduce en reivindicaciones políticas, que hacen parte del giro hacia el reconocimiento y el estatus como ciudadanas. Así, para la autora, este giro representa una nueva interpretación de la justicia de género, la cual abarca ahora temas de representación, identidad y diferencia, que sirven para profundizar y enriquecer las luchas por una redistribución igualitaria. Por ello, Fraser propone una teoría social comprometida con la democracia y la justicia desde una postura de género que impulse la idea de la justicia como paridad participativa. Se trata de promover una "revisión de la democracia y la justicia que tenga en cuenta las cuestiones de género" (p. 18).

Dentro de las reivindicaciones actuales, varias autoras han hablado acerca del futuro del feminismo. Una de ellas es Martha Lamas quien en la conferencia "Machismo y política" expresa:

"La nueva agenda del feminismo no se está ocupando de que las mujeres tengan cargos públicos porque ya los están teniendo, este es un proceso imparable", al que la ley de cuotas ${ }^{8}$ ha hecho un aporte indiscutible, "sino más bien de que los hombres no están haciendo su parte de corresponsabilidad en el espacio de lo privado"; y cita a Gøsta Esping-Andersen: "Para cerrar la brecha entre mujeres y hombres, hay que lograr que el ciclo de vida de los hombres se parezca más al de las mujeres. (Flacso México, 2014)

Por otra parte, Chantal Mouffe, en entrevista con el periodista Jorge Alemán, critica la visión esencialista de la mujer y plantea que el objetivo del populismo de izquierda en la actualidad es construir un pueblo a través de la articulación de una serie de demandas democráticas que son heterogéneas: "La articulación de las diferentes demandas de las mujeres y de los diferentes sectores sociales es

aquellas que se alejan del círculo imaginario de la sexualidad "normal" y que ejercen su derecho a proclamar su existencia (Fonseca y Quintero, 2009).

8 En 1991, por iniciativa de mujeres activistas de la Unión Cívica Radical y del peronismo, Argentina fue pionera en el diseño de cuotas electorales que obligaron a incorporar candidatas en las listas de todos los partidos políticos. La Ley 24012 (de cupo femenino) fue determinante para ampliar la participación femenina en el Congreso y ubicó al país como un modelo para otros Estados (Caminotti, 2013). Esta iniciativa se convirtió en un hito para la representación política de las mujeres en el poder legislativo, ya que, a partir de ese momento, la adopción de medidas de acción afirmativa se extendió no solo en la región, sino en el mundo. Para noviembre de 2016, en América Latina, 15 países habían sancionado leyes de cuotas: Argentina (1991), México (1996), Paraguay (1996), Bolivia (1997), Brasil (1997), Costa Rica (1997), Ecuador (1997), Panamá (1997), Perú (1997), República Dominicana (1997), Venezuela (1998), Colombia (1999), Honduras (2000), Uruguay (2009) y Chile (2015) (Martelotte, 2016). 
crucial para alcanzar dicho objetivo; la lucha feminista puede volverse el símbolo de todas las otras luchas, pero no puede ser diferenciada del resto" (Punto de Emancipación, 2018).

En ese mismo orden de ideas, Marcela Lagarde, en la conferencia sobre la sororidad, expresa:

El feminismo no aspira a ser un discurso único ni total; por el contrario, ha contribuido a abrir corrientes en el pensamiento del mundo contemporáneo (ambientalismo, ecologismo, alternativas económicas); la apuesta actual es por sumar fuerzas entre todos los movimientos democráticos por la vida y la libertad de las mujeres. (Concejalía de Feminismo y Diversidad Fuenlabrada, 2013)

Entre las aspiraciones existentes, se resaltan estudios feministas como el de Mestre-Malfran y Oliveira (2020) que abogan por el reconocimiento de la ciudadanía trans, puesto que todo ser humano tiene derecho a vivir el género a partir de sus identidades y referencias múltiples, con lo cual plantea fisuras en los discursos que defienden el lugar de los sujetos en la vida pública a partir de determinismos biologicistas. Por tanto, se considera la necesidad de que las políticas públicas planteen perspectivas de género e interseccional que contribuyan a entender la ciudadanía trans desde las realidades políticas y culturales que ayuden en todo caso a transformar las situaciones de opresión e injusticia social.

El protagonismo público de las cuestiones que reivindican los feminismos se constata, por ejemplo, en el primer paro internacional de mujeres, llevado a cabo el 8 de marzo de 2018 e inmortalizado como \#8M (Entremujeres, 2018). Este paro fue convocado por organizaciones feministas y aliadas de la lucha por los derechos de las mujeres en todo el mundo y participaron más de 150 países en contra de la violencia de género, la brecha salarial, el control sobre los cuerpos, el trabajo de cuidados no pago, las crecientes cifras de feminicidios, la guerra y toda dominación sobre las mujeres: "pero no se limita a una huelga formal, sino que también quienes trabajamos en los hogares estamos invitadas a parar y asi evidenciar el valor del tiempo y el trabajo no pago que realizamos" (Colombia Informa, 2019).

Para entender el potencial que tienen las redes sociales en las reivindicaciones políticas de los movimientos feministas, Acosta (2018) afirma que, por ejemplo, el aborto en Argentina ha sido un fenómeno de opinión pública y discursiva que da cuenta de las posibilidades de la democracia deliberativa en América Latina. Así, bajo el hashtag \#AbortoLegalYa y la página de Facebook de la Campaña Nacional por el Derecho al Aborto Legal, Seguro y Gratuito, señala que actual- 
mente existen "nuevos instrumentos de participación cívica, formas estratégicas de comunicación y organización colectiva mediadas por la tecnopolítica [...] que posibilitan una dinámica de participación [que permite] desafiar no solo las estructuras sociales tradicionales sino también a los poderes políticos" (pp. 16-17).

Estos reclamos de grupos históricamente oprimidos y los cambios sociales, culturales, económicos, tecnológicos y políticos generados en los últimos tiempos, según autoras como Leonor Brown (2009), han ido moviendo fronteras entro lo público y lo privado, redefiniendo y complejizando la comprensión sobre estos ámbitos de actuación de los sujetos, ampliando los límites que en un momento dado se construyeron desde una visión liberal de la política. Así, por ejemplo, las sexualidades comienzan a ser objeto de debate público y político, y se abre el espectro sobre su legitimidad. En este sentido, los temas personales, subjetivos y particulares se constituyen ahora en asuntos de interés y movilización ciudadana y conquistan un espacio del ágora política.

De este modo, lo que ha hecho el feminismo es darle un vuelco al concepto de ciudadania, que, si bien ha sido cambiante a lo largo de la historia debido a los procesos democráticos de cada época, relegó a la mujer por siglos a un segundo plano, incluso durante el origen y desarrollo de la teoría liberal, que precisamente nació en defensa de la libertad y la igualdad de todo ser humano ante la ley, pero olvidó que "donde hay desigualdad, la libertad puede encontrarse escrita en las leyes, en el estatuto, pero no es una cosa real” (De Sanctis, 1951, p. 6). Situación que alentó a las mujeres a

comenzar a cuestionar lo que se ha atribuido como tareas propias de las mujeres, que hayan construido un discurso filosófico y político diciendo no queremos ser lo que se considera femenina, queremos también tener las tareas y atribuciones de los hombres, queremos entrar en el espacio público, haciendo toda una revisión y una crítica de la feminidad como cuestión natural. (Flacso México, 2014)

Así las cosas, este recorrido ha mostrado que el concepto de ciudadanía ha tenido diferentes connotaciones, pasando de grupos privilegiados, hasta llegar, al fin, a todos los sectores de la población. Las mujeres hicieron gala de la modernidad y reclamaron la reivindicación de los derechos negados durante siglos, de ahí se desprende una lucha que después de dos siglos y medio continúa con diferentes reclamaciones, pero con la misma fuerza, perfeccionando sus postulados y articulándose con poblaciones que, al igual que la mujer, han sobrellevado la imposibilidad de ser visibles e identificado la importancia que tiene agruparse para ser vistos y escuchados. 


\section{Conclusiones}

El recorrido por el concepto de ciudadanía permite observar la manera en que este ha sido configurado durante la historia y que no ha sido, por tanto, un concepto estático; por el contrario, cada época ha modificado la forma de participar en la construcción del orden social y designado a las personas que participarían en tal construcción. La revisión documental sugiere que la ciudadanía es en sí misma un concepto de interés académico, ya que todos los textos analizados abordan marcos teóricos e históricos para describir las dinámicas de poder y las relaciones jurídicas, estructurales y cotidianas entre las personas que alcanzan las categorías de ciudadanos y las que no.

De manera similar, se encuentra un desarrollo histórico en la ciudadanía de las mujeres que permite reconocer los discursos y las acciones políticas alrededor de la ampliación o limitación de derechos a este grupo poblacional. Así pues, en los textos revisados, hay una tendencia a los análisis de casos que describen luchas, procesos y perspectivas propias de poblaciones con contextos específicos. Hecho que permite considerar que las mujeres, además de otros grupos poblacionales como indígenas, afroamericanos, grupos poblacionales diversos (LGBTTTI: Lesbiana, gay, bisexual, transgénero, transexual, travesti, intersexual y queer), entre otros, apropian la categoría de ciudadana según las identidades, las condiciones sociales, las posibilidades de participación política y las condiciones estructurales.

Consecuentemente, se observa una relación entre ciudadanía y participación política, en la medida en que la categoría de ciudadanía facilita o inhibe la posibilidad de participar en la estructuración política. En este punto, también cabe mencionar que las luchas feministas consideran la relación ciudadano-participación política, lo cual se hace evidente en los textos que abordan participación política y percepción de género de forma paralela. Sus reclamos consideran la participación en las instituciones políticas y el reconocimiento como sujetos pensantes y actuantes con vida propia. Así, los documentos analizados permiten concluir que el feminismo como fundamento teórico ha aportado a la ciencia política a través del estudio en profundidad y con rigurosidad de las demandas, las prácticas políticas, sociales, familiares y culturales, y las diferencias dentro del grupo de las mujeres.

Para finalizar, el acercamiento textual a diferentes autores da cuenta del amplio recorrido teórico que se ha hecho, el interés que evoca indagar y traer de la memoria histórica a la actualidad el proceder político de las mujeres a partir de sus especificidades, conocer el presente de sus demandas y señalar la vigencia que tiene en la actualidad en los estudios de la ciencia política. 
130 | Yuly Andrea Ramírez Osorio y Jenny Marcela Acevedo Valencia

Ciudadanía de las mujeres: una revisión desde la ciencia política

\section{Referencias}

Acevedo Valencia, J. M. y Castaño Torres, S. (2020). Mujeres excombatientes de las FARC-EP: experiencias y significados del espacio público-privado. Hegemonia: Revista Eletrônica do Programa de Mestrado em Direitos Humanos, Cidadania e Violência, 30, 134-169. http://www.unieuro.edu.br/sitenovo/revistas/revista_hegemonia_30/Jenny\%20Acevedo\%20(7).pdf

Acosta, M. (2018). Ciberactivismo feminista: la lucha de las mujeres por la despenalización del aborto en Argentina. Sphera Publica, 2(18), 2-20. http://sphera.ucam.edu/ index.php/sphera-01/article/view/347

Aguado, A. (2005). Ciudadanía, mujeres y democracia. Historia Constitucional, 6, 11-27. https://www.redalyc.org/pdf/2590/259027572001.pdf

Bárcena, F. (1997). El oficio de la ciudadanía: introducción a la educación política. Paidós.

Benhabib, S. (1992). Una revisión del debate sobre las mujeres y la teoría moral. Isegoría, 6, 37-63. https://doi.org/10.3989/isegoria.1992.i6.323

Berger, P. y Luckmann, T. (1983). La sociedad como realidad objetiva: la sociedad como realidad subjetiva. Amorrortu.

Bobbio, N. (1989). Liberalismo y democracia. Fondo de Cultura Económica.

Caminotti, M. E. (2013). La representación política de las mujeres en el periodo democrático. Revista SAAP, 7(2), 329-337. https://ri.conicet.gov.ar/handle/11336/92280

Cano, J. E. (2017). Elementos para (re)pensar la ciudadanía de las mujeres y la (re)formulación del antagonismo. Revista Jurídica Universidad de Palermo, 1, 57-78. https://www. palermo.edu/derecho/revista_juridica/pub-15/Revista_Juridica_Ano15-N1_03.pdf

Colombia Informa. (2019, 8 de marzo). 8M: Si las mujeres paran, se para el mundo. http://www.colombiainforma.info/8m-si-las-mujeres-paran-se-para-el-mundo/

Concejalía de Feminismo y Diversidad Fuenlabrada. (2013, 21 de abril). Conferencia de Marcela Lagarde sobre la sororidad [Video]. YouTube. https://www.youtube.com/ watch?v=8CKCCy6R2_gSororidad

Constant, C. (2019). Cambio legal de identidad y ciudadanía de mujeres trans en México: algunas experiencias. Revista de la Facultad de Derecho de México, 69(275-2), 787-808. http://dx.doi.org/10.22201/fder.24488933e.2019.275-2.71479

Corena, A. y Suárez, J. (2018). Ciudadanía restringida de las mujeres víctimas del conflicto armado en Colombia debido a las barreras de acceso a la justicia. Inclusión y Desarrollo, 5(2), 39-62. https://doi.org/10.26620/uniminuto.inclusion.5.2.2018.39-62

De Puelles Benítez, M. y Urzúa Fradermann, R. (1996). Educación, gobernabilidad democrática y gobernabilidad de los sistemas educativos. Revista Iberoamericana de Educación, 12, 107-135. https://doi.org/10.35362/rie1201152

De Sanctis, F. (1951). Mazzini e la scuola democratica. Einaudi.

Dietz, M. G. y Vericat, I. (1990). El contexto es lo que cuenta: feminismo y teorías de la ciudadanía. Debate Feminista, 1, 114-140.

Entremujeres. (2018, 3 de diciembre). Desde la cuarta ola: ¿cuáles son las cuatro olas del feminismo en la historia? https://www.clarin.com/entremujeres/genero/mujeres-feminismo-ola-feminista_0_N-yPg4mar.html

Fonseca Hernández, C. M. y Quintero Soto, M. L. (2009). La teoría queer: la de-construc- 
Yuly Andrea Ramírez Osorio y Jenny Marcela Acevedo Valencia | 131 Ciudadanía de las mujeres: una revisión desde la ciencia política

ción de las sexualidades periféricas. Revista Sociológica, 24(69), 43-60. http://www. scielo.org.mx/scielo.php?script=sci_arttext\&pid=S0187-01732009000100003

Flacso México. (2014, 14 de febrero). Machismo y política [Video]. YouTube. https:// www.youtube.com/watch?v=fYUo_TLN05A

Fraser, N. (2015). Fortunas del feminismo: del capitalismo gestionado por el Estado a la crisis neoliberal. Instituto de Altos Estudios Nacionales del Ecuador.

Gil, S. L. (2012, 2 de mayo). Nuevos feminismos: sentidos comunes en la dispersión [Video]. YouTube. https://www.youtube.com/watch?v=K0OeJTjAL3g\&t=2525s

Guerra Martinière, M. (2019). ¡Somos ciudadanas! Ciudadanía y sufragio femenino en el Perú. Histórica, 43(1), 180-183. https://doi.org/10.18800/historica.201901.009

Habermas, J. (1987). Teoría de la acción comunicativa. Taurus.

Hobbes, T. (1980). El Leviatán. Deusto.

Jiménez Betancourt, R. (2004). Feminismo y género: develando mitos. En C. E. Gómez Velásquez, J. F. Vélez Granada, R. Jiménez Betancourt y R. Fernández Andrade, Develando mitos: ensayos sobre subjetividad y ciudadanía. Corporación Región para el Desarrollo y la Democracia.

Kymlicka, W. (1996). Ciudadanía multicultural. Paidós.

Lau Jaiven, A. y Rodríguez Bravo, R. (2017). El sufragio femenino y la Constitución de 1917: una revisión. Política y Cultura, 48, 57-81. http://www.scielo.org.mx/scielo. php? script $=$ sci_arttext\&pid $=$ S0188-77422017000200057

Leonor Brown, J. (2009). Los derechos (no) reproductivos y sexuales en los bordes entre lo público y lo privado: algunos nudos del debate en torno a la democratización de la sexualidad. Sexualidad, Salud y Sociedad: Revista Latinoamericana, 2, 10-28. https://www.redalyc.org/pdf/2933/293322969002.pdf

Lister, R. (2004). Citizenship and gender. Blackwell.

Locke, J. (2006). Segundo tratado del gobierno civil. Alianza.

Manzanera Román, S., Ortiz García, P. y Clavero Mira, E. (2015). Las repercusiones de la crisis sobre la posición de la mujer inmigrante en España. Arxius de Ciències Socials, 32, 173-184. https://roderic.uv.es/handle/10550/49029

Marshall, T. H. y Bottomore, T. B. (1998). Ciudadanía y clase social. Losada.

Martelotte, L. (2016). 25 años de la aplicación de leyes de cuotas en América Latina: un balance de la participación política de las mujeres. Sur: Revista Internacional de Derechos Humanos, 13(24), 91-98.

Mayor Zaragoza, F. (2003). Ciudadanía democrática: reinventar la democracia, la cultura de paz, la formación cívica y el pluralismo. En F. Imbernón (coord.), Cinco ciudadanías para una nueva educación (pp. 15-27). Graó.

Mestre-Malfran, Y. y Oliveira, J. M. (2020). Un abordaje interseccional de la ciudadanía trans en Cuba. Psicología Política, 20(48), 448-461. https://repositorio.iscte-iul.pt/ handle/10071/20753

Mieles Barrera, M. D. y Alvarado Salgado, S. V. (2012). Ciudadanías y competencias ciudadanas. Estudios Políticos, 40, 53-75. https://www.redalyc.org/pdf/164/16429068004.pdf

Mouffe, C. (1999). El retorno de lo político: comunidad, ciudadanía, pluralismo y democracia radical. Paidós.

Mouffe, C. y Moreno, H. (1993). Feminismo, ciudadanía y política democrática radical. Debate Feminista, 7, 3-22. 
132 | Yuly Andrea Ramírez Osorio y Jenny Marcela Acevedo Valencia Ciudadanía de las mujeres: una revisión desde la ciencia política

Olsen, F. (2000). En sexo del derecho. En A. E. C. Ruiz (comp.), Identidad femenina y discurso jurídico (pp. 25-42). Biblos.

Parrado Morales, S. y Isidro, L. (2014). La paradoja hipócrita: problematización de la participación política de la mujer misak. Colombia Internacional, 80, 135-170. http://dx.doi.org/10.7440/colombiaint80.2014.05 X

Phillips, A. (1996). ¿Deben las feministas abandonar la democracia liberal? En Perspectivas feministas en teoría política (pp. 79-98). Paidós.

Posada Zapata, I. C. y Carmona Parra, J. A. (2018). Political subjectivity and women citizenship in contexts of armed conflicts. Revista Mexicana de Ciencias Políticas y Sociales, 63(233), 69-92. https://doi.org/10.22201/fcpys.2448492xe.2018.233.57835

Punto de Emancipación. (2018, 27 de junio). Jorge Alemán 06 - Chantal Mouffe: Populismo y feminismo [Video]. YouTube. https://www.youtube.com/watch?v=RI79|5G5OJQ

Rousseau, J. (1985). El Emilio (J. Marchena, trad.). Club Internacional del Libro (original publicado en 1762).

Sánchez Fontalvo, I. M. (2006). Educación para una ciudadanía democrática e intercultural en Colombia (Tesis doctoral, Universidad de Barcelona). https://www.tdx.cat/ handle $/ 10803 / 2348 \#$ page $=1$

Sánchez Muñoz, C. (2019). Constitución y género o la inconclusa igualdad de las mujeres. Eunomía: Revista en Cultura de la Legalidad, 17, 377-381. https://doi. org/10.20318/eunomia.2019.5041

Sen, C. (2018, 11 de noviembre). El feminismo sube a la cuarta ola. La Vanguardia. https://www.lavanguardia.com/vida/20181111/452836533674/feminismo-basesmovimiento-espana-cuarta-ola.html

Scoot, J. (2015). El género: una categoría útil para el análisis histórico. En M. Lamas (comp.), El género: la construcción cultural de la diferencia sexual (pp. 251-290). Bonilla Artigas.

Solé, C., Serradell, O. y Sordé, T. (2013). Ciudadanía en femenino: aportaciones de las mujeres inmigrantes marroquíes, ecuatorianas y rumanas en España. Revista de Estudios Sociales, 47, 51-66. http://dx.doi.org/10.7440/res47.2013.04

Suárez Molano, J. O. (2004). Syllabus sobre la filosofía política. Universidad Pontifica Bolivariana. 